\title{
Towards a Smart Encapsulation System for Small-Sized Electronic Devices: A New Approach
}

\author{
Sebastian-Tim Schmitz-Hertzberg, ${ }^{1,2}$ Rick Liese, ${ }^{1}$ Carsten Terjung, ${ }^{1}$ and Frank F. Bier ${ }^{1,2}$ \\ ${ }^{1}$ Fraunhofer Institute for Biomedical Engineering IBMT, Branch Potsdam, Am Muehlenberg 13, 14476 Potsdam, Germany \\ ${ }^{2}$ Institute for Biochemistry and Biology, University of Potsdam, Karl-Liebknecht-Straße 24-25, 14476 Potsdam, Germany \\ Correspondence should be addressed to Sebastian-Tim Schmitz-Hertzberg; sebastian.schmitz-hertzberg@ibmt.fraunhofer.de
}

Received 11 October 2013; Revised 19 December 2013; Accepted 20 December 2013; Published 9 February 2014

Academic Editor: Qijin Zhang

Copyright (c) 2014 Sebastian-Tim Schmitz-Hertzberg et al. This is an open access article distributed under the Creative Commons Attribution License, which permits unrestricted use, distribution, and reproduction in any medium, provided the original work is properly cited.

\begin{abstract}
Miniaturized analytical chip devices like biosensors nowadays provide assistance in highly diverse fields of application such as point-of-care diagnostics and industrial bioprocess engineering. However, upon contact with fluids, the sensor requires a protective shell for its electrical components that simultaneously offers controlled access for the target analytes to the measuring units. We therefore developed a capsule that comprises a permeable and a sealed compartment consisting of variable polymers such as biocompatible and biodegradable polylactic acid (PLA) for medical applications or more economical polyvinyl chloride (PVC) and polystyrene (PS) polymers for bioengineering applications. Production of the sealed capsule compartments was performed by heat pressing of polymer pellets placed in individually designable molds. Controlled permeability of the opposite compartments was achieved by inclusion of $\mathrm{NaCl}$ inside the polymer matrix during heat pressing, followed by its subsequent release in aqueous solution. Correlating diffusion rates through the so made permeable capsule compartments were quantified for preselected model analytes: glucose, peroxidase, and polystyrene beads of three different diameters $(1.4 \mu \mathrm{m}, 4.2 \mu \mathrm{m}$, and $20.0 \mu \mathrm{m})$. In summary, the presented capsule system turned out to provide sufficient shelter for small-sized electronic devices and gives insight into its potential permeability for defined substances of analytical interest.
\end{abstract}

\section{Introduction}

Electronic devices with complex analytical functionalities such as biosensors mark an efficient opportunity for the monitoring of medical diagnostic or bioprocess engineering applications [1-5]. Nevertheless, appropriate handling usually requires a protective layer that is placed between the sensor device and its surrounding analyte containing fluids to prevent the occurrence of electrical shorts on active components. The layer should further inhabit specific material properties depending on the individual purpose of the biosensor. For use in medical applications the sensor should, for example, be protected by a biocompatible shell to prevent harmful inflammatory reactions inside the host.

Synthesis, modification, and validation of appropriate biocompatible substances have been widely studied during the past decades [6-8]. Since first artificial bone replacing grafts and implantable drug delivery systems were realized, focus has been laid on further improvement of these material classes. Amongst them, calcium phosphate minerals like hydroxylapatite and biodegradable polymers such as thermoplastic aliphatic poly(esters) represent the most potential options $[6,7,9-16]$.

Hydroxylapatite belongs to a group of bioactive substances which are chemically similar to the mineral components of bones and hard tissues. The applicability of hydroxylapatite components for integration in such scaffolds has already made them suitable for use as bone fillings [7]. Another field of potential interest involves bioceramic coatings that are often applied to metallic implants. Furthermore, hydroxylapatite is known for its substitution of a negatively charged hydroxyl group by fluoride, chloride, or carbonate that can be exploited to produce various kinds of apatite with diverging attributes [7]. On the other hand, hydroxylapatite deposits are known to cause calcific tendinitis [17] and bulk items have a rather stiff ductility. For some specific 
applications it is therefore required to replace its properties by a synthetic polymer.

Accordingly poly(lactic-co-glycolic acid) copolymers (PLGA) and polylactic acid (PLA) were extensively investigated due to their biocompatibility and plasticity as well as customizable attributes, like sensitivity towards degradation and flexibility [11-14]. While PLA is often derived from corn starch PLGA is usually produced via a ring-opening copolymerization using tin(II) alkoxides or aluminium isopropoxide as catalysts. Their nontoxic, nonimmunogenic, and noncarcinogenic biodegradation products are metabolites that could be eliminated via the tricarboxylic acid cycle [8]. In addition, the glass transition temperatures $\left(T_{g}\right)$ of PLGA and PLA polymers lie above the human body temperature of $37^{\circ} \mathrm{C}$ so that they are stable against heat induced deformation during fixation in a human host. Supported by mechanical strength, due to a fairly rigid chain structure, they are also able to overcome physical stress during general application in living organisms [8]. Choosing the right crystallinity, as well as variations of type, molecular weight and mixing ratios of the individual monomer components (lactic acid and glycolic acid) allow further modifications of the polymer properties for different scenarios. These affect not only its mechanical strength, but also the swelling behavior, the capacity to undergo hydrolysis, and the subsequent biodegradation rates of the polymer [8]. Accordingly, validation, troubleshooting, and balancing of the so modified material properties were optimized and published in multiple reports with special focus on the degradation and drug release behavior of block copolymers [14] including a nonlactic acid based component, as well as pure PLA and PLGA compositions $[15,16]$ with different molecular weight [18].

In addition, several related biomimetic materials and their modifications have been investigated. These include variations of biologically and chemically optimized composites [12] comprising combinations of both PLGA and hydroxyapatite [9]. Focus was also laid on the development of composites with improved attributes such as PGAchitosan matrixes [19], PLGA structures with releasable content $[20,21]$, or modified gelatin scaffold properties by agent-containing PLGA particle incorporation [22-24].

The encapsulation of advanced biosensors for assistance in medical diagnostics such as point-of-care testing now requires a biocompatible shield for simultaneous protection of the biosensor combined with a certain permeability to allow the transfer of distinct analytes into the capsule for detection and quantification. Appropriate porous scaffolds have already been obtained from biocompatible polymers like PGA $[25,26]$ before but were often yielded by solid state polymerization techniques that offer limited influence on shape and density of the final item. In turn custom designed components with optionally modified material attributes are usually produced by injection molding of melted polymers resulting in minor control over their porosity [27-29].

The encapsulation of implantable biosensors, however, requires both, a partially porous shell design that is adaptable to shape and volume of an individual sensor device. Accordingly, our aim was the development of a more flexible capsule production method that offers molding opportunities for various permeable components made of biocompatible and nonbiocompatible polymers such as poly(lactic-co-glycolic acid) copolymers (PLGA), polylactide (PLA), polyvinyl chloride (PVC), and polystyrene (PS) that diverge in attributes such as stiffness, glass transition temperatures and hydrolytic degradation properties. The technique demonstrated in the following part is based on heat pressing of composites consisting of polymer powder blends mixed with water soluble extender materials (porogen) such as sodium chloride particles. It is therefore possible to predefine size and shape of the final encapsulation system by choosing appropriate molds for the pressing procedure. In previous works, similar methods were already successfully applied to create individual implants for the reconstruction of skull defects [30] or to obtain bulky PLA-PGA objects for biodegradation studies [31].

Final release of the porogen out of the thermoformed components upon incubation in water ended up in a formation of pore clusters causing a respective permeability of the remaining polymer matrix through which diffusion rates of variously sized model analytes were subsequently measured.

\section{Materials and Methods}

The LaboPress P200S was purchased from Vogt Labormaschinen $\mathrm{GmbH}$, Germany. Diamond-like carbon (DLC) coating of molding masters was done by Härterei Hauck GmbH, Germany. The ultracentrifuge mill ZM 200 and screening machine AS 200 were bought from RETSCH, Germany. The RM 2245 microtome was built by Leica. PLGA (Resomer RG 504, Resomer RG 750 S) and PLA (Resomer R 203 H, Resomer R 207 S, Resomer L 210) polymers were obtained from Evonik Röhm GmbH, Germany. The Spurr Low Viscosity Embedding Kit was purchased from VWR International $\mathrm{GmbH}$, Germany. Horseradish peroxidase, glucose oxidase from Aspergillus niger, and tetramethylbenzidine (TMB) were bought from Sigma Aldrich, Germany. Polystyrene (PS) beads were received from Polysciences, Inc. Common lab materials like dichloromethane (DCM), sodium chloride $(\mathrm{NaCl})$, and glucose were purchased from Carl Roth GmbH \& Co. KG, Germany.

2.1. Composite Preparation. Thermoforming of the capsule compartments was achieved by heat pressing of premixed composites that consisted of various ratios of a polymer and an extender substance $(\mathrm{NaCl})[30,31]$. Therefore, seven different polymers (Table 1) were first chopped by a ZM 200 ultracentrifuge mill (RETSCH) at $8000 \mathrm{rpm}$. Depending on the initial rigidity of the different materials the polymers were cut down to particles of fine powder quality by using sieves with a narrow mesh size (here: $0.75 \mathrm{~mm}$ ). To prevent melting and aggregation of the polymer particles during the heat producing milling process the bulk material was cooled in liquid nitrogen and together with this transferred into the mill.

Sodium chloride served as extender material and was thoroughly ground using mortar and pistil. Subsequent partition of the amorphous particles was done by a screening 
TABLE 1: Overview over the different polymer/ $\mathrm{NaCl}$ blends produced by manual mixing or precipitation from solid-in-oil dispersions.

\begin{tabular}{|c|c|c|c|c|c|c|c|}
\hline \multirow{2}{*}{ Composite preparation } & \multirow{2}{*}{ Polymer } & \multicolumn{6}{|c|}{$\mathrm{NaCl}$ amount (weight \%) } \\
\hline & & 30 & 40 & 60 & 65 & 70 & 80 \\
\hline \multirow{6}{*}{ Mixed manually (m) } & Resomer RG 504 (PLGA $50: 50$ ) & & & & & ? & \\
\hline & Resomer RG 750 S (PLGA 75 : 25) & & & - & $\bullet$ & • & • \\
\hline & Resomer R 207 S (PLA) & & & & & & • \\
\hline & Resomer L 210 (PLA) & $\bullet$ & $\bullet$ & $\bullet$ & & & \\
\hline & polyvinyl chloride (PVC) & & & $\bullet$ & $\bullet$ & $\bullet$ & \\
\hline & polystyrene (PS) & & & $\bullet$ & - & & \\
\hline \multirow{5}{*}{ Precipitation $(\mathrm{p})$} & Resomer RG 504 (PLGA 50 : 50) & & & - & & • & \\
\hline & Resomer RG 750 S (PLGA 75 : 25) & & & & & $\bullet$ & • \\
\hline & Resomer R 207 S (PLA) & & & & & ○ & ○ \\
\hline & Resomer L 210 (PLA) & & & - & $\bullet$ & • & \\
\hline & Resomer R 207 S + L 210 (1:1) (PLA) & & & & & $\bullet$ & \\
\hline
\end{tabular}

machine AS 200 (RETSCH) through sieves with a mesh size of $50 \mu \mathrm{m}$. Different polymer $/ \mathrm{NaCl}$ composites were then mixed in various ratios (Table 1 ).

An alternative method for the production of $\mathrm{NaCl} / \mathrm{PLGA}$ and $\mathrm{NaCl} / \mathrm{PLA}$ powder composites was developed. For this $3.0 \mathrm{~g}$ of either PLGA or PLA was first dissolved in $100 \mathrm{~mL}$ dichloromethane. According to the required polymer/ $\mathrm{NaCl}$ ratio (Table 1 ) the respective amount of ground sodium chloride powder was then added to the hydrophobic solution under stirring conditions to form a solid-in-oil (s/o) dispersion. Subsequent pouring of $200 \mathrm{~mL}$ ethanol (96\%) into the stirred dispersion forced fast precipitation of the polymer followed by its aggregation around the $\mathrm{NaCl}$ particles. Finally the yield was cooled in liquid nitrogen and cut inside the ZM 200 using the standard sieve of $0.75 \mathrm{~mm}$ mesh size, as well.

2.2. Capsule and Test Disc Production. In the following step $2.0 \mathrm{~g}$ of each composite (Table 1) was transferred into a stainless steel mold of ellipsoid-shape with an inert diamondlike carbon (DLC) layer coating on the surface for capsule production. In addition, disc-shaped specimens were made using $0.5 \mathrm{~g}$ of each composite placed in an uncoated brass mold (Scheme 1).

A LaboPress P200S compactor was used for heat pressing of both specimen kinds. The process was performed stepwise, starting with 1500 bar applied pressure at $80^{\circ} \mathrm{C}$ for test discs made of PLGA or PLA composites $\left(150^{\circ} \mathrm{C}\right.$ for test discs made of PVC or PS composites) for $30 \mathrm{sec}$ under vacuum conditions ( $50 \mathrm{mbar}$ absolute pressure). Within this time interval the applied pressure was abruptly removed and immediately rebuilt within two seconds for three times to release entrapped gas from the compressed composite particles. Main sintering of the specimens was then performed at 2500 bar for 870 seconds under constant temperature conditions.

2.3. Visual Porosity Control of the Specimen. After preparation the bulk specimens were detached from the mold surfaces and placed in beakers filled with water to extract the porogen $(\mathrm{NaCl})$ from the polymer matrix. Therefore, the
(1) Mold made of stainless steel with diamond-like-carbon (DLC) coating on relevant parts of the topography for capsule production

(2) Mold made of brass for test disc production
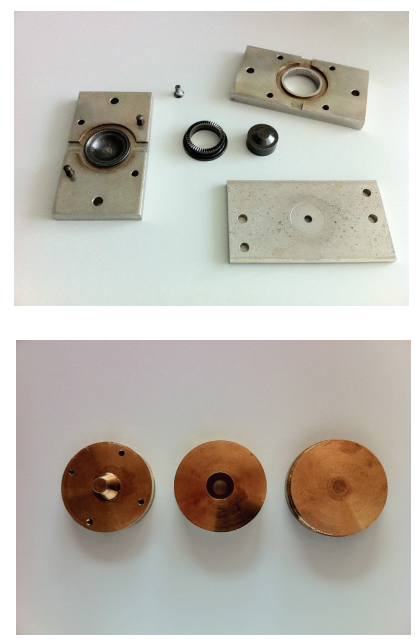

SCHEME 1: Molds used for specimen production of two different forms.

specimens were incubated at $100 \mathrm{rpm}$ overnight and dried afterwards. The extender release efficiency and decreased density of the specimens were then defined by quantification of their weight loss.

Furthermore, microscopic imaging was performed for visual control of the pore distribution within the remaining polymer matrix. For this each sample was first embedded in $2 \mathrm{~mL}$ "Spurr low viscosity resin" which then was solidified during incubation at $70^{\circ}$ for 4 hours. Afterwards $10 \mu \mathrm{m}$ slices were cut from the specimens using a RM 2245 microtome (Leica) and steel blades with diamond coating. Final imaging of the samples was done using an IX51 microscope (OLYMPUS) with a $4.0 x$ lens.

2.4. Evaluation of the Specimen Permeability. The permeability of each porous test disc made from the composites listed in Table 1 was further evaluated by monitored diffusion rates of different sized analytes through the specimen. Three model analytes were chosen for the study: glucose (180 Da), 
TABLE 2: Experimental setup for each model analyte.

\begin{tabular}{|c|c|c|c|}
\hline Model analyte & Detection by & Content of chamber 1 & Content of chamber 2 \\
\hline Glucose & Amperometry & $\begin{array}{c}100 \mu \mathrm{L} \text { glucose solution }(1 \mathrm{M}) \\
5 \mu \mathrm{L} \text { ferrocenecarboxylic acid }(10 \mathrm{mg} / \mathrm{mL}) \\
1895 \mu \mathrm{L} 150 \mathrm{mM} \text { PBS buffer }(\mathrm{pH} 7.46)\end{array}$ & $\begin{array}{c}10 \mu \mathrm{L} \text { glucose oxidase } \\
(150 \mathrm{mg} / \mathrm{mL}) \\
5 \mu \mathrm{L} \text { ferrocenecarboxylic acid }(10 \mathrm{mg} / \mathrm{mL}) \\
1985 \mu \mathrm{L} 150 \mathrm{mM} \text { PBS buffer }(\mathrm{pH} 7.46)\end{array}$ \\
\hline Horseradish peroxidase & $\mathrm{TMB}$ reaction assay & $\begin{array}{c}2000 \mu \mathrm{L} \text { peroxidase }(1 \mathrm{mg} / \mathrm{mL}) \text { in citric } \\
\text { buffer }(\mathrm{pH} 4.43)\end{array}$ & $2000 \mu \mathrm{L}$ citric buffer ( $\mathrm{pH} 4.43$ ) \\
\hline Polystyrene (PS) beads & Flow cytometry & $\begin{array}{c}\text { Polystyrene beads } \\
\varnothing 1.4 \mu \mathrm{m}=1.4 * 10^{9} / \mathrm{mL} \\
\varnothing 4.2 \mu \mathrm{m}=4.9 * 10^{7} / \mathrm{mL} \\
\varnothing 20.0 \mu \mathrm{m}=1.1 * 10^{5} / \mathrm{mL} \\
\text { in } 2000 \mu \mathrm{L} \text { isotonic buffer }\end{array}$ & $2000 \mu \mathrm{L}$ isotonic buffer \\
\hline
\end{tabular}

horseradish peroxidase $(44 \mathrm{kDa})$, and polystyrene particles of three different diameters $(1.4 \mu \mathrm{m}, 4.2 \mu \mathrm{m}$, and $20.0 \mu \mathrm{m})$.

The diffusion test setup was based on an exclusively designed diffusion cell that consisted of two chambers with a volume of $2 \mathrm{~mL}$ each. Both chambers were interconnected via a narrow fluid channel $(\varnothing 5.0 \mathrm{~mm})$. While chamber 1 contained predetermined concentrations of the model analyte in buffer, chamber 2 was filled with pure buffer only. The test discs were fixed inside sealing rings and placed within the fluid channel between both chambers to allow analyte diffusion through the polymer discs from chamber 1 to chamber 2 (Figure 1).

The diffusion related increase of analyte concentration in chamber 2 was monitored by application of appropriate detection methods and reagents placed inside the diffusion cell (Table 2). Hydrostatic pressure was balanced between the chambers by a fixed overall sample volume of $2 \mathrm{~mL}$ on both sides.

First glucose molecule diffusion through the specimen was measured amperometrically under stirring conditions $(300 \mathrm{rpm})$ via the enzymatic reaction of glucose with glucose oxidase $[32,33]$ that could be monitored continuously by an Autolab PGSTAT12/30 Differential Electrometer Amplifier with a fixed potential of $0.5 \mathrm{~V}$ for a time interval of up to 3 hours. The used test setup (Table 2) consisted of a standard gold electrode (working electrode), a platinum wire (counter electrode), and a $\mathrm{Ag} / \mathrm{AgCl}$ electrode (reference) placed directly in chamber 2 of the diffusion cell during measurements. Quality of the gold electrode performance was controlled by cyclic voltammogram traces after each sample measurement. Furthermore, signal interfering accumulations of reaction products on the gold electrode surface were periodically removed according to an established cleaning procedure taken from the literature [34].

Quantification of diffused peroxidase molecules through the specimen was subsequently based on the colorimetric tetramethylbenzidine (TMB) reaction assay $[35,36]$. For this $30 \mu \mathrm{L}$ aliquots were taken from chamber 2 at time intervals of $1,2,3,6$, and 24 hours of incubation time. Each sample was mixed with $30 \mu \mathrm{L}$ of $\mathrm{TMB}, 30 \mu \mathrm{L}$ of hydrogen peroxide, and $210 \mu \mathrm{L}$ citric buffer ( $\mathrm{pH} 4.43)$ in a microtiter plate. A reaction based color shift of the samples and correlating increase of

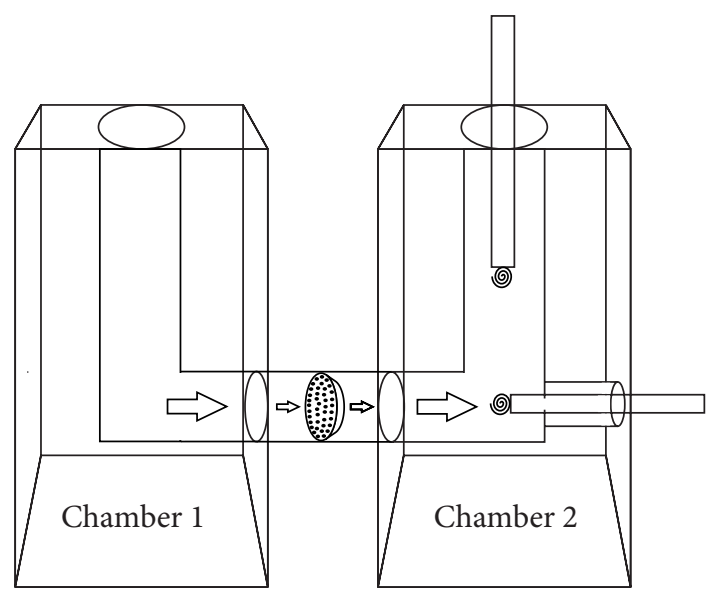

FIGURE 1: Diffusion cell consisting of two chambers with fixed specimen within the interconnecting channel.

absorbance were recorded at $630 \mathrm{~nm}$ for a time interval of 10 min using a BMG Labtech FLUOstar Omega plate reader.

At last the time depending diffusion behavior of PS beads with three different diameters (Table 2) through the specimen was evaluated by quantification of accumulated particles in chamber 2 of the diffusion cell. The respective aliquots were taken from chamber 2 after incubation intervals of 1, 2, 3, 6, and 24 hours on a shaker at $100 \mathrm{rpm}$ and then analyzed by a Beckman Coulter-Cytomics FC 500 flow cytometer used for particle counting.

\section{Results and Discussion}

3.1. Prepared Capsules and Test Discs. According to size and shape of the used stainless steel mold the polymer capsule specimens consisted of two identical compartments with a jagged ring structure, an overall diameter of $3 \mathrm{~cm}$, and maximum height of $1 \mathrm{~cm}$ (Scheme 2). The ring structure was chosen for better alignment of two half-compartments before bonding with biocompatible epoxy glue. The ellipsoid capsule design further enclosed a hollow center part that offered an outer surface to inner volume ratio of around $22.8 \mathrm{~cm}^{2}$ to 


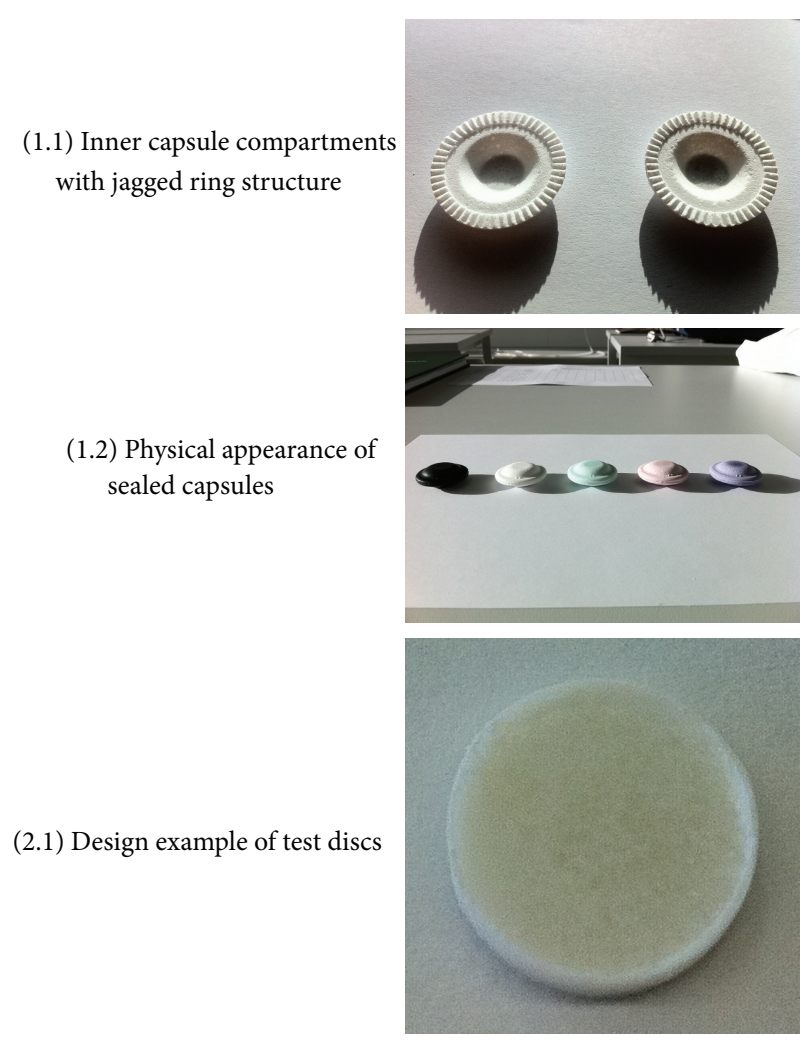

Scheme 2: Capsule/test disc appearance.

$1.8 \mathrm{~cm}^{3}$ for storage of plane chips with a bulky center part. It is important to note that the capsule design could easily be changed by a replacement of the mold that was used for heat pressing of the specimen drafts. The presented design, however, is just a random example to demonstrate proper applicability of the method.

3.2. Obtained Shell Layer Porosity. To reveal quantity and distribution of pores within the capsule profile, the disc-shaped specimens made of various $\mathrm{NaCl} /$ polymer compositions according to Table 1 with a diameter of $1 \mathrm{~cm}$ and thickness of around $2.5 \mathrm{~mm}$ (Scheme 2) were embedded in resin. Due to its low viscosity the resin could penetrate the porous polymer surface to fill and stabilize the whole specimen from within. Due to their improved rigidity slices could then be cut from the specimen with a microtome knife without causing grinding and destabilization effects of their inner profile. As expected subsequent analysis via microscope imaging revealed individual pore distributions inside the specimen that consisted of differently prepared composites according to Table 1. In the end, a classification into three main categories was possible. The first class involved specimens that were made of manually mixed PS and Resomer L 210 composites with a large polymer particle size above $500 \mu \mathrm{m}$. Unlike the other PLGA and PLA polymers used in this study Resomer L 210 did not consist of soft fibers or fibrous flakes but particles of high stiffness. Further decrease of the polymer particle size by comminution inside the ultracentrifuge mill would have required adequate mechanical strength for cutting that is usually associated with an increasing local temperature on the surface of the cutting tools. Since Resomer L 210 and PS have a glass transition temperature $\left(T_{g}\right)$ of $55-60^{\circ} \mathrm{C}$ (Resomer L 210) and $60-100^{\circ} \mathrm{C}$ (PS) the heat generation inside the centrifuge mill during cutting caused deformations and agglomeration of the crushed particles. Although these effects were significantly decreased by simultaneous cooling of the polymer material and cutting tools with liquid nitrogen, practical considerations limited the lowest achievable particle size for these polymers to around $500 \mu \mathrm{m}$ since necessary efforts as well as the required volume of liquid nitrogen would have had an inefficient work to yield balance.

Pressing of manually mixed $\mathrm{NaCl}$ /polymer composites with comparatively large polymer particles now led to an increased aggregation of salt particles inside the specimen that was followed by a rather inhomogeneous distribution of pores (Figure 2(a)). While fluid diffusion through samples of this kind was supported by gaps between adjacent particles, a concurrent decrease of the overall stability could be observed.

In contrast to that a sufficient homogenization and decrease of particle size for composites based on Resomer L 210 were achieved by conversion of the solid particle morphology to soft, fibrous flakes via precipitation of the polymer. In the following the material was cut into powder sized particles using the ultracentrifuge mill. Upon extender release from specimens prepared of these composites they showed a sponge-like inner structure of low elasticity that was clearly distinguishable from those pressed out of the larger Resomer L 210 particles (Figure 2(b)).

In contrast to that, specimen derived from homogenous powder composites based on RG 504 revealed a coalesced state of the composite particles after heat pressing; that is, former contact areas of single particles were untraceably fused. Furthermore, numerous spherical cavities of different size were left upon release of the porogen. Unlike the specimens made of Resomer L 210 both specimen profiles made of RG 504 had a similar optical appearance that were independent of the previously applied composite mixing technique (Figures 2(c) and $2(\mathrm{~d})$ ).

Meanwhile the inner structure of RG $750 \mathrm{~S}$ specimens appeared with combined properties of the precipitated L 210 as well as RG 504 composite samples by showing a partially sponge-like surface with spherical cavities (Figures 2(e) and 2(f)).

Similar results were also observed for the polystyrene specimens as presented in Figure 2(g).

However, PVC showed high affinity to melting during the incubation in resin at $70^{\circ} \mathrm{C}$. Proper specimen slices for visual profile analysis could therefore not be obtained.

3.3. Physical Specimen Properties. Of each selected composite mixture (Table 1) three test discs were produced and the releasable $\mathrm{NaCl}$ content quantified by measuring the weight loss of each specimen after incubation in water for $24 \mathrm{~h}$. Furthermore the diffusion distance for analytes through the specimen was defined by measuring the thickness of the remaining polymer layer with a caliper. Both attributes turned out to be strongly depending on predefined composite 


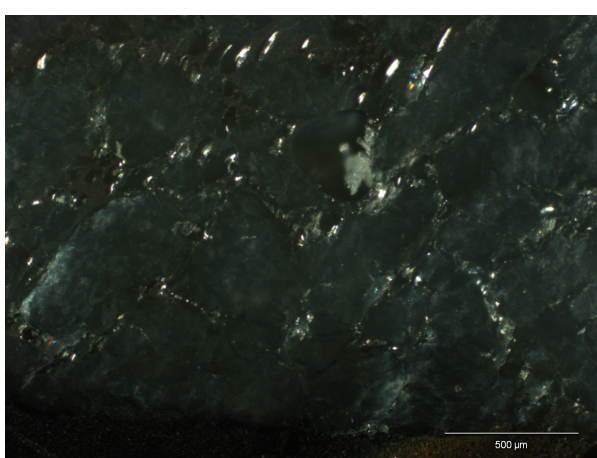

(a)

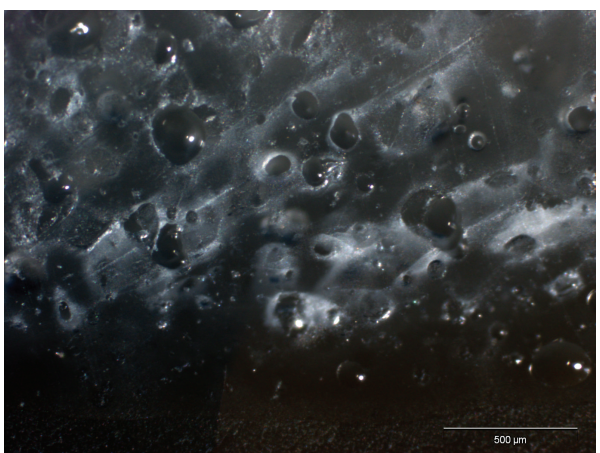

(c)

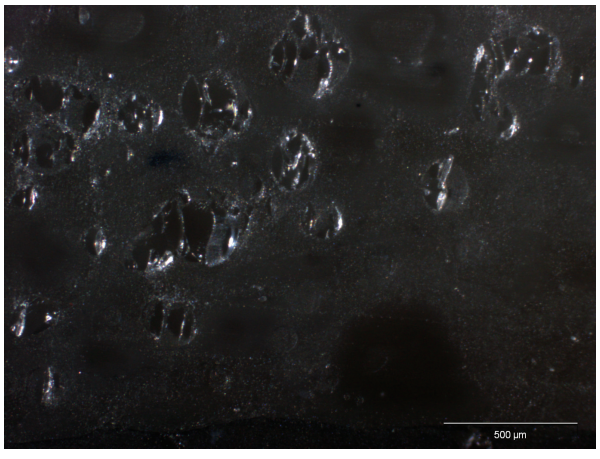

(e)

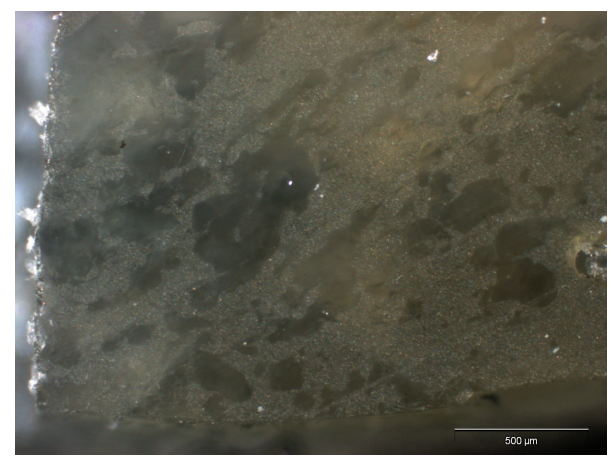

(b)

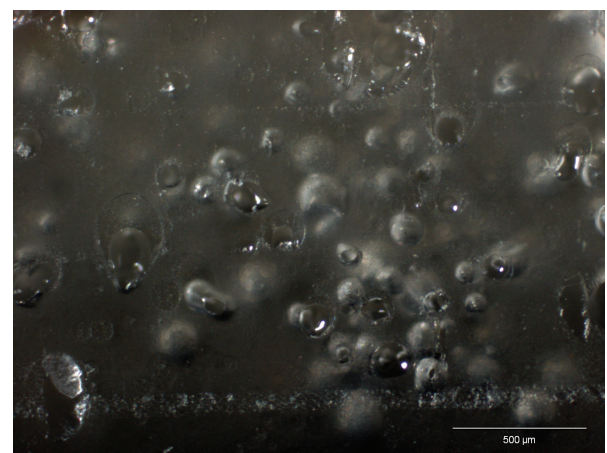

(d)

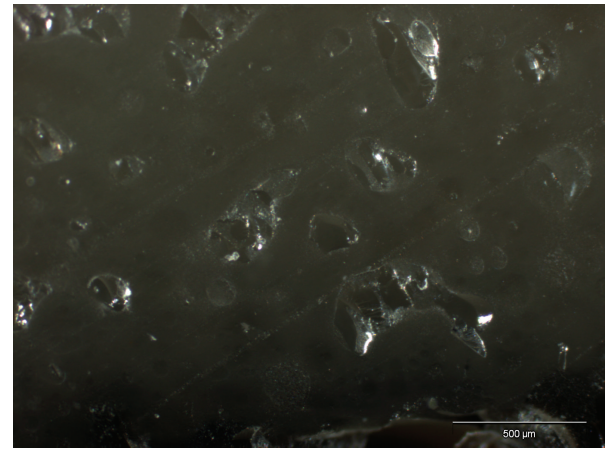

(f)

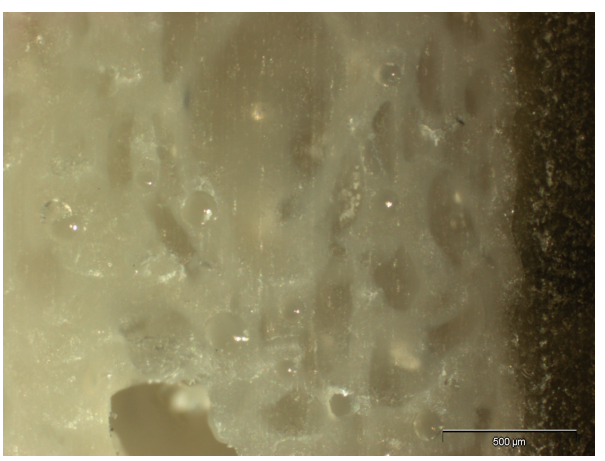

(g)

FIGURE 2: Pore distribution after porogen release from various specimens; scale bar: $500 \mu \mathrm{m}$. (a) Resomer L 210 (m)* $40: 60$ (NaCl: PLA) specimen. (b) Resomer L 210 (p)* $70: 30$ (NaCl: PLA) specimen. (c) Resomer RG $504(\mathrm{~m})^{*} 70: 30$ (NaCl: PLGA) specimen. (d) Resomer RG $504(\mathrm{p})^{*} 70: 30$ (NaCl: PLGA) specimen. (e) Resomer RG 750 S (m)* $75: 25$ (NaCl: PLGA) specimen. (f) Resomer RG 750 S (p)* $70: 30$ $\left(\mathrm{NaCl}:\right.$ PLGA) specimen. (g) Polystyrene $(\mathrm{m})^{*} 65: 35(\mathrm{NaCl}: \mathrm{PS})$ specimen. ${ }^{*}:(\mathrm{m})=$ mixed manually $/(\mathrm{p})=$ precipitated. 
TABLE 3: Measured thickness and calculated $\mathrm{NaCl}$ release of selected specimen blends.

\begin{tabular}{|c|c|c|c|c|c|}
\hline \multirow[b]{2}{*}{ Measured parameter } & \multicolumn{5}{|c|}{ Specimen composition } \\
\hline & $\begin{array}{c}\operatorname{PVC~}(\mathrm{m})^{*} \\
(70: 30) \\
(\mathrm{NaCl}: \mathrm{PVC})\end{array}$ & $\begin{array}{c}\text { PS (m) }{ }^{*} \\
(65: 30) \\
(\mathrm{NaCl}: \mathrm{PS})\end{array}$ & $\begin{array}{c}\mathrm{L} 210(\mathrm{~m})^{*} \\
(40: 60) \\
(\mathrm{NaCl}: \mathrm{PLA})\end{array}$ & $\begin{array}{c}\mathrm{L} 210(\mathrm{p})^{*} \\
(70: 30) \\
(\mathrm{NaCl}: \mathrm{PLA})\end{array}$ & $\begin{array}{c}\text { RG } 504(\mathrm{p})^{*} \\
(70: 30) \\
(\mathrm{NaCl}: \text { PLGA) }\end{array}$ \\
\hline $\begin{array}{l}\text { Mean release of } \mathrm{NaCl} \\
\text { compound (\%) }\end{array}$ & 100 & 92 & 85 & 92 & 96 \\
\hline $\begin{array}{l}\mathrm{SD} \text { of mean released } \mathrm{NaCl} \\
\text { compound }(\%)\end{array}$ & 1.74 & 0.91 & 6.90 & 0.89 & 0.50 \\
\hline Mean thickness $d(\mathrm{~mm})$ & 2.30 & 2.60 & 3.18 & 2.56 & 2.51 \\
\hline $\begin{array}{l}\text { SD of mean thickness } d \\
(\mathrm{~mm})\end{array}$ & 0.05 & 0.16 & 0.02 & 0.03 & 0.30 \\
\hline
\end{tabular}

$*(\mathrm{~m})=$ mixed manually $/(\mathrm{p})=$ precipitated.

material properties like the particle size of the polymer components, as well as the amount of formerly entrapped extender particles (Table 3).

In particular, specimens that consisted of more than $70 \%$ (w/w) $\mathrm{NaCl}$ were partially fragile after release of the porogen in water. Samples containing more than $80 \%$ (w/w) $\mathrm{NaCl}$ were already brittle after preparation and before release of the $\mathrm{NaCl}$ amount from the polymer matrix. In contrast to that specimens made of composites based on $\mathrm{NaCl}$ concentrations below $65 \%(\mathrm{w} / \mathrm{w})$ were insufficiently permeable for molecule diffusion. Hence further test runs were focused on $\mathrm{NaCl} /$ polymer composites with a porogen ratio between 65 and $80 \%$ with the only exception of manually mixed L 210 composites that had a $\mathrm{NaCl}$ ratio of $40 \%$. According to Figure 2 these test discs showed a very rough specimen structure that led to expectations for an increased permeability.

3.4. Glucose Diffusion Measurement. Glucose diffusion was successfully observed within threefold test runs for specimen made of PVC (m) 70:30, PS (m) 65:35, Resomer L 210 (m) $40: 60$, Resomer L 210 (p) $70: 30$, and Resomer RG 504 (p) $70: 30$ composites (Table 4). Diffusion coefficients were determined based on

$$
D=\frac{d^{2}}{(2 * t)},
$$

where $D$ marks the diffusion coefficient, $d$ the layer thickness of the specimen, and $t$ the time needed until diffusion of glucose molecules was measureable.

The highest diffusion coefficient of $1.53 * 10^{-9} \mathrm{~m}^{2} / \mathrm{s}$ (Table 4) was experimentally verified for specimen made of PS (m) $65: 35$ composites. Samples made of Resomer L 210 (m) 40:60 composites showed the second fastest transfer of glucose through the test discs with an average diffusion coefficient of $6.13 * 10^{-5} \mathrm{~cm}^{2} / \mathrm{s}$. Minor deviations between both specimen types could be related to their different layer thickness, the ratio of released $\mathrm{NaCl}$ from the polymer matrix, and interactions of the diffusing molecules with the polymer surfaces. The results also correspond to the rough structured polymer scaffolds that were caused by the larger polymer particles used for molding of these samples. The latter also led to minimized compression of the specimen followed by the comparatively highest specimen thickness of $3.18 \mathrm{~mm}$ for the Resomer L 210 (m) $40: 60$ samples and $2.60 \mu \mathrm{m}$ for the PS (m) $65: 35$ composites (Table 3 ). However, the generally low porogen release from the Resomer L 210 (m) 40:60 samples of $85 \%$ (Table 3 ) could be explained by isolated $\mathrm{NaCl}$ particles that were completely surrounded by a significantly larger amount of the polymer ratio.

The lowest diffusion coefficient of $0.94 * 10^{-9} \mathrm{~m}^{2} / \mathrm{s}$ was meanwhile measured by specimen made of PVC (m) 70:30 composites although $100 \%$ of the porogen was released from the polymer matrix combined with the lowest specimen thickness of $2.30 \mathrm{~mm}$. This might have been caused by retention of the glucose molecules on the PVC surface, as well as compaction of the test discs to a higher density with reduced pore volume of the polymer scaffold.

For test discs made of precipitated Resomer L 210 (p) $70: 30$ and Resomer RG 504 (p) $70: 30$ composites a similar layer thickness, ratio of released porogen, and correlating diffusion coefficients were measured (Tables 3 and 4). Hereby the specimens made of Resomer L 210 (p) $70: 30$ composites were further promising to match utilization standards in industry and medical diagnostics due to a low standard deviation of less than $10 \%$ determined by threefold test runs.

In summary the measured diffusion coefficients for the specimens listed in Table 4 were ten times higher than comparative data measured for diffusion through similar membrane structures taken from the literature [37-40]. Since measurement of diffused glucose molecules inside the diffusion cell was depending on homogenously distributed reactants, the solutions were kept under continuous stirring conditions. Hereby it is likely that the glucose molecules had been transferred through the test discs together with the moving solvent.

Due to the initial glucose concentration of $50 \mathrm{mmol} / \mathrm{L}$ in chamber 1 of the diffusion cell, continuous diffusion of glucose molecules through the test discs should furthermore have led to a time depending equilibration of both fluid chambers to end up in a balanced concentration of $25 \mathrm{mmol} / \mathrm{L}$. Actual results match these expectations as presented in Figure 3(a). 
TABLE 4: Diffusion coefficients of glucose molecules through test discs of various blends at $20^{\circ} \mathrm{C} ; D_{\text {glucose }}$ in $0.1 \mathrm{M}$ sodium phosphate buffer at $25^{\circ} \mathrm{C}(\mathrm{pH} 6.7): 0.72 * 10^{-5} \mathrm{~cm}^{2} / \mathrm{s}[37]$.

\begin{tabular}{|c|c|c|c|c|c|}
\hline \multirow[b]{2}{*}{ Measured parameter } & \multicolumn{5}{|c|}{ Specimen composition } \\
\hline & $\begin{array}{c}\mathrm{PVC}(\mathrm{m})^{*} \\
(70: 30) \\
(\mathrm{NaCl}: \mathrm{PVC})\end{array}$ & $\begin{array}{c}\text { PS (m)* } \\
(65: 30) \\
(\mathrm{NaCl}: \mathrm{PS}) \\
\end{array}$ & $\begin{array}{c}\mathrm{L} 210(\mathrm{~m})^{*} \\
(40: 60) \\
(\mathrm{NaCl}: \mathrm{PLA})\end{array}$ & $\begin{array}{c}\mathrm{L} 210(\mathrm{p})^{*} \\
(70: 30) \\
(\mathrm{NaCl}: \mathrm{PLA})\end{array}$ & $\begin{array}{c}\text { RG } 504(\mathrm{p})^{*} \\
(70: 30) \\
(\mathrm{NaCl}: \text { PLGA })\end{array}$ \\
\hline$n$ (test runs) & 3 & 3 & 3 & 3 & 3 \\
\hline$D$ (glucose) $\left(10^{-10} * \mathrm{~m}^{2} \mathrm{~s}^{-1}\right)$ & 9.40 & 15.30 & 61.30 & 12.30 & 20.90 \\
\hline $\begin{array}{l}\mathrm{SD} D \text { (glucose) }\left(10^{-10} *\right. \\
\left.\mathrm{m}^{2} \mathrm{~s}^{-1}\right)\end{array}$ & 3.70 & 4.50 & 4.50 & 1.90 & 17.80 \\
\hline
\end{tabular}

$*(\mathrm{~m})=$ mixed manually $/(\mathrm{p})=$ precipitated.

TABLE 5: Diffusion coefficients of peroxidase molecules through test discs of various compositions at $20^{\circ} \mathrm{C}$.

\begin{tabular}{|c|c|c|c|c|c|}
\hline \multirow[b]{2}{*}{ Measured parameter } & \multicolumn{5}{|c|}{ Specimen composition } \\
\hline & $\begin{array}{c}\mathrm{PVC}(\mathrm{m})^{*} \\
(70: 30) \\
(\mathrm{NaCl}: \mathrm{PVC})\end{array}$ & $\begin{array}{c}\text { PS (m)* } \\
(65: 30) \\
(\mathrm{NaCl}: \mathrm{PS})\end{array}$ & $\begin{array}{c}\mathrm{L} 210(\mathrm{~m})^{*} \\
(40: 60) \\
(\mathrm{NaCl}: \mathrm{PLA})\end{array}$ & $\begin{array}{c}\mathrm{L} 210(\mathrm{p})^{*} \\
(70: 30) \\
(\mathrm{NaCl}: \mathrm{PLA})\end{array}$ & $\begin{array}{c}\text { RG } 504(\mathrm{p})^{*} \\
(70: 30) \\
(\mathrm{NaCl}: \text { PLGA })\end{array}$ \\
\hline$n$ (test runs) & 3 & 3 & 3 & 3 & 3 \\
\hline $\begin{array}{l}D \text { (peroxidase) }\left(10^{-10} *\right. \\
\left.\mathrm{m}^{2} \mathrm{~s}^{-1}\right)\end{array}$ & 2.87 & 6.48 & 14.05 & 4.59 & 8.86 \\
\hline $\begin{array}{l}\text { SD } D \text { (peroxidase) }\left(10^{-10} *\right. \\
\left.\mathrm{m}^{2} \mathrm{~s}^{-1}\right)\end{array}$ & 3.64 & 5.40 & 0.18 & 4.05 & 2.17 \\
\hline
\end{tabular}

3.5. Peroxidase Diffusion Measurement. In the next step specimens of previously verified permeability for glucose molecules $(0.18 \mathrm{kDa})$, which were made of PVC $(\mathrm{m}) 70: 30$, PS (m) 65:35, Resomer L 210 (m) 40:60, Resomer L 210 (p) 70:30, and Resomer RG 504 (p) 70:30 composites (Table 4 ), were tested with focus on diffusion rates of peroxidase $(44 \mathrm{kDa})$ in time intervals of $1,2,3,6$, and 24 hours (Figure 3(b)).

Accordingly diffusion coefficients and final concentrations of accumulated peroxidase in chamber 2 of the diffusion cell after 24 hours were calculated, too (Table 5).

In correlation to the experimentally proven glucose diffusion, peroxidase diffusion was successfully tested within threefold test runs through all specimen compositions. Amongst these, samples made of Resomer L 210 (m) 40:60 composites showed the highest diffusion coefficient of 14.05 $* 10^{-10} \mathrm{~m}^{2} / \mathrm{s}$ due to their rough structured polymer matrix as described earlier. Contrary to the diffusion coefficients published for peroxidase in aqueous solution by Fatima and Husain [41] the measured values inside the diffusion cell were once again ten times higher as observed for glucose diffusion before.

Further support of previously achieved results was indicated by the significantly lower diffusion coefficient determined for specimen made of PVC (m) 70:30 composites of $2.87 * 10^{-10} \mathrm{~cm}^{2} / \mathrm{s}$. Here the higher condensed polymer layer of the test discs obviously seemed again to have strong effects on the measured molecule transfer.

In direct comparison to the previous specimen an average diffusion coefficient of $6.48 * 10^{-10} \mathrm{~cm}^{2} / \mathrm{s}$ was observed for samples made of PS (m) $65: 35$ composites. But unlike the other specimens, no significant increase of the diffused peroxidase concentration could be observed after $1 \mathrm{~h}$ incubation of these test discs inside the diffusion cell.

In contrast to that a diffusion coefficient of $8.86 *$ $10^{-10} \mathrm{~cm}^{2} / \mathrm{s}$ was measured for Resomer RG 504 (p) $70: 30$ specimens that led to a balanced peroxidase concentration between both chambers of the diffusion cell within 6 hours of incubation.

A continuous increase of diffusing peroxidase was meanwhile observed for Resomer L 210 (p) 70 : 30 test discs during incubation for 24 hours. Nonetheless here the significantly lower diffusion coefficient of $4.59 * 10^{-10} \mathrm{~cm}^{2} / \mathrm{s}$ prevented the accumulation of an equally high peroxidase concentration in chamber 2 of the diffusion cell as measured for the Resomer RG 504 (p) $70: 30$ specimens.

In summary the highly different diffusion rates determined for each sample confirmed that all prepared specimens had an individual character regarding their porosity independent of the composite used as basic material. At this stage of development the capsules do therefore provide sufficient permeability for larger molecules such as enzymes but have limitations with respect to an exact determination of the analyte concentration in their environment. Accordingly, further studies should evaluate how diffusion rates on the capsule surface may be equalized by application of thinner polymer layers of various compositions. Furthermore it is necessary to monitor whether changing environmental conditions like flow pressure on the capsule surface, as it appears, for example, during fixation in drainpipes or stirred vessels, could correlate with increased diffusion rates.

3.6. Polystyrene Beads Diffusion Measurement. Polystyrene beads were chosen as third model analyte to examine the 


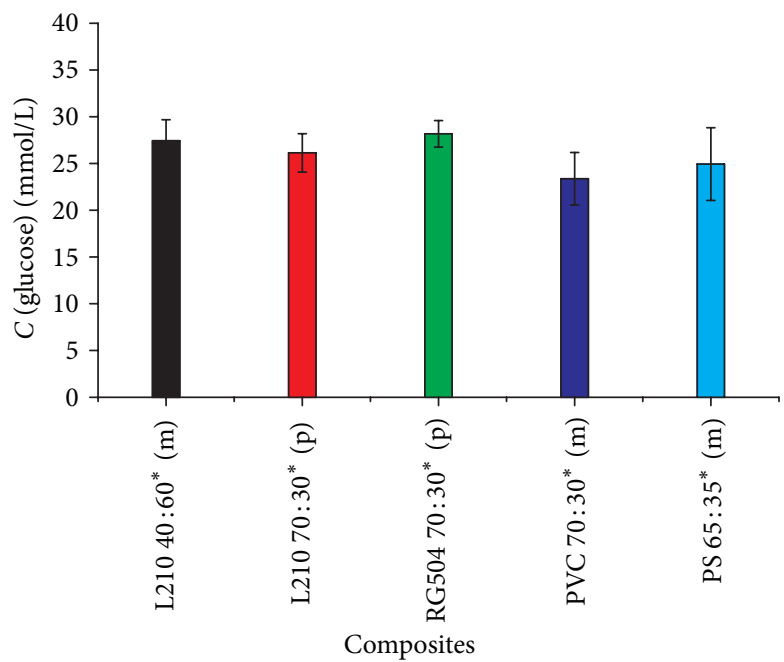

(a)

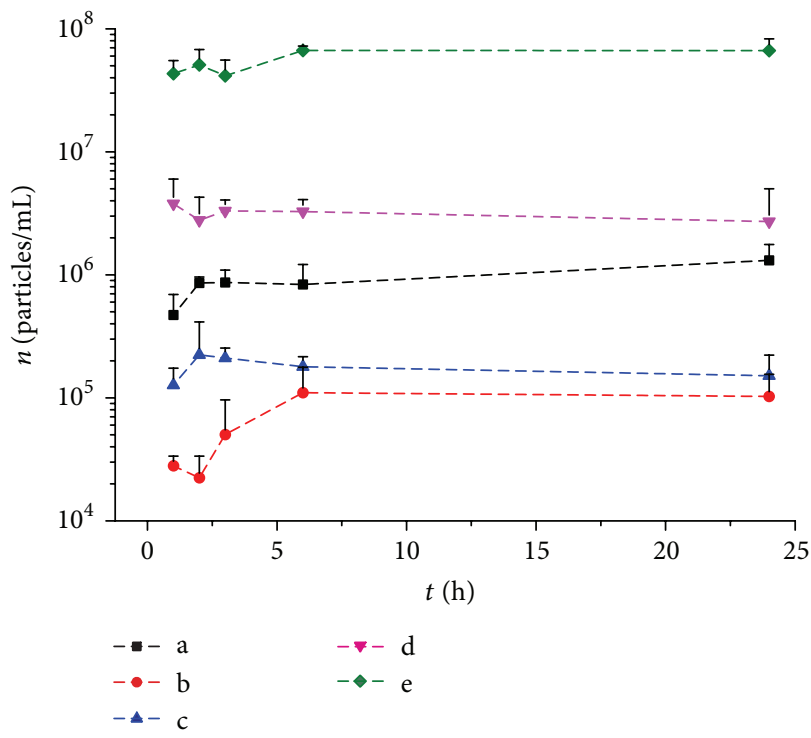

(c1)

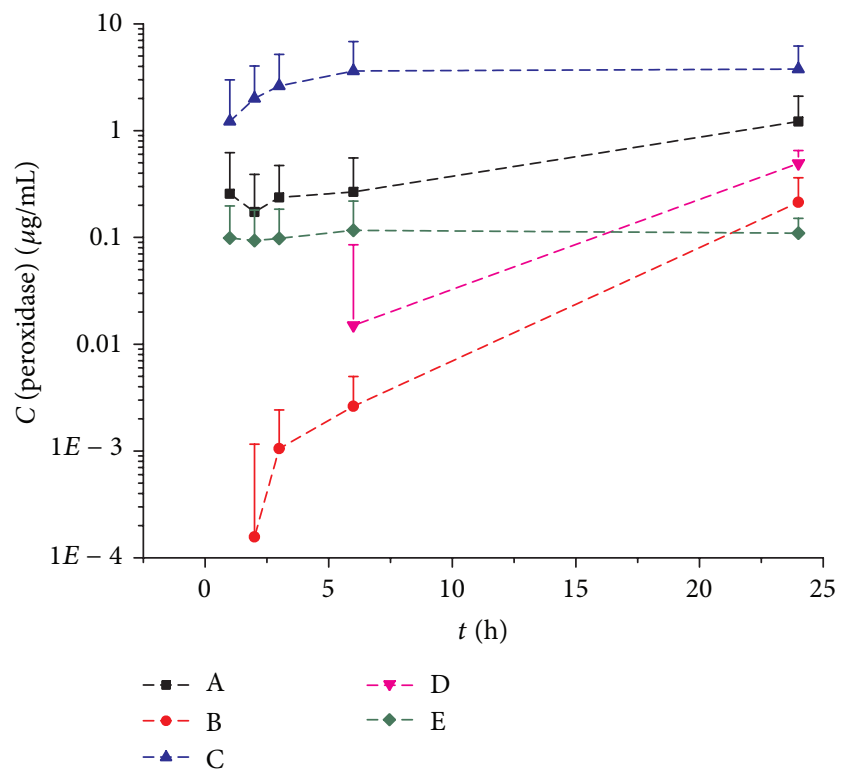

(b)

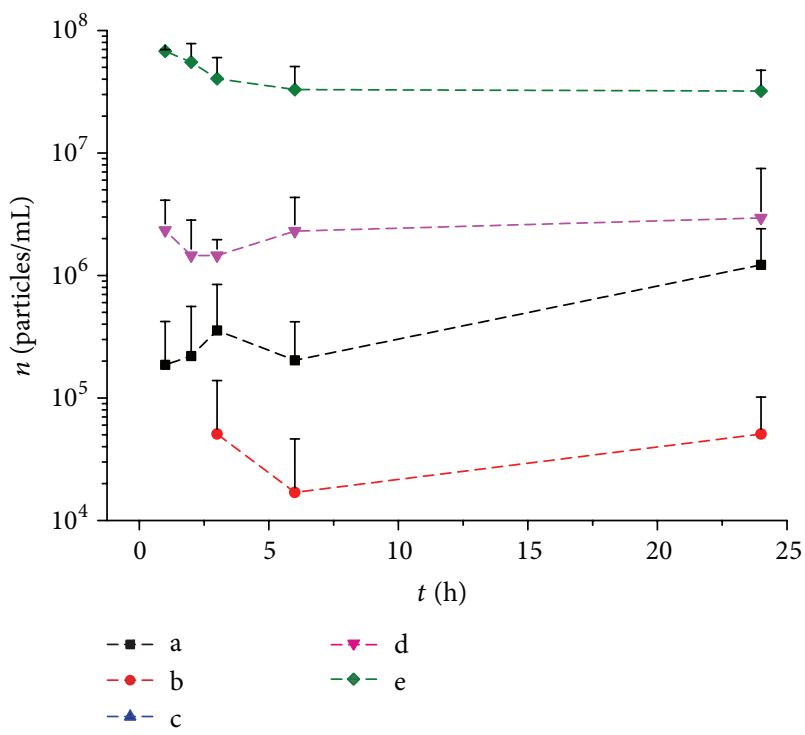

(c2)

(c)

FIGURE 3: (a) Average glucose concentration in $\mathrm{mmol} / \mathrm{L}$ at equilibrium in chamber 2 of the diffusion cell after diffusion through test discs of various compositions. (b) Average peroxidase concentration $(\mu \mathrm{g} / \mathrm{mL})$ in chamber 2 of the diffusion cell after $1 \mathrm{~h}, 2 \mathrm{~h}, 3 \mathrm{~h}, 6 \mathrm{~h}$, and $24 \mathrm{~h}$ diffusion through test discs of various composition; A: Resomer L 210 (m) 40:60, B: Resomer L 210 (p) $70: 30$, C: Resomer RG 504 (p) $70: 30$, D: PVC (m) 70:30, E: PS (m) 65:35. (cl) Polystyrene bead $(\varnothing 1.4 \mu \mathrm{m})$ counts in chamber 2 of the diffusion cell after $1 \mathrm{~h}, 2 \mathrm{~h}, 3 \mathrm{~h}, 6 \mathrm{~h}$, and $24 \mathrm{~h}$ diffusion through test discs of various composition; A: $\varnothing 1,4 \mu \mathrm{m} / \mathrm{B}: \varnothing 4,2 \mu \mathrm{m}$; a: Resomer L 210 (m) 40:60, b: Resomer L 210 (p) $70: 30$, c: Resomer RG 504 (p) $70: 30$, d: PVC (m) $70: 30$, e: PS (m) $65: 35$. (c2) Polystyrene bead $(\varnothing 4.2 \mu \mathrm{m})$ counts in chamber 2 of the diffusion cell after $1 \mathrm{~h}, 2 \mathrm{~h}, 3 \mathrm{~h}, 6 \mathrm{~h}$, and $24 \mathrm{~h}$ diffusion through test discs of various composition; A: $\varnothing 1,4 \mu \mathrm{m} / \mathrm{B}: \varnothing$ 4,2 $\mu \mathrm{m}$; a: Resomer L 210 (m) $40: 60$, b: Resomer L 210 (p) $70: 30$, c: Resomer RG 504 (p) $70: 30$, d: PVC (m) $70: 30$, e: PS (m) $65: 35$.

capsule properties regarding their permeability for particles of various sizes, that is, if they work as a filter layer for larger objects. First PS beads with a diameter of $1.4 \mu \mathrm{m}$ were used as substitute for bacteria cells with a similar volume such as E. coli. In addition, the diffusion rate of PS beads with a diameter of $4.2 \mu \mathrm{m}$, that is, comparable to the size of erythrocytes, was analyzed. Both cell types represent analytes of possible relevance for the final sensor capsule application. Furthermore, a third fraction of PS beads with a diameter of $20 \mu \mathrm{m}$ was utilized to specify the prospected maximum diffusion capacity of the system.

PS beads from these batches within a concentration range from $10^{5}$ (Ø $20.0 \mu \mathrm{m}$ ), respectively, $10^{7}$ (Ø $4.2 \mu \mathrm{m}$ ) to $10^{9}$ (Ø $1.4 \mu \mathrm{m}$ ) particles $/ \mathrm{mL}$ were transferred into the diffusion cell. 
TABLE 6: Diffusion coefficients/counts of polystyrene beads through test discs of various blends at $20^{\circ} \mathrm{C}$.

\begin{tabular}{|c|c|c|c|c|c|}
\hline \multirow[b]{2}{*}{ Measured parameter } & \multicolumn{5}{|c|}{ Specimen composition } \\
\hline & $\begin{array}{c}\mathrm{PVC}(\mathrm{m})^{*} \\
(70: 30) \\
(\mathrm{NaCl}: \mathrm{PVC})\end{array}$ & $\begin{array}{c}\mathrm{PS}(\mathrm{m})^{*} \\
(65: 30) \\
(\mathrm{NaCl}: \mathrm{PS})\end{array}$ & $\begin{array}{c}\mathrm{L} 210(\mathrm{~m})^{*} \\
(40: 60) \\
(\mathrm{NaCl}: \mathrm{PLA})\end{array}$ & $\begin{array}{c}\mathrm{L} 210(\mathrm{p})^{*} \\
(70: 30) \\
(\mathrm{NaCl}: \mathrm{PLA})\end{array}$ & $\begin{array}{c}\text { RG } 504(\mathrm{p})^{*} \\
(70: 30) \\
(\mathrm{NaCl}: \text { PLGA })\end{array}$ \\
\hline$n$ (test runs) $\varnothing_{\text {particle }} 1.4 \mu \mathrm{m}$ & 3 & 3 & 3 & 3 & 3 \\
\hline $\begin{array}{l}D \text { (PS particles) }\left(10^{-10} *\right. \\
\left.\mathrm{m}^{2} \mathrm{~s}^{-1}\right)\end{array}$ & 7.33 & 9.39 & 14.05 & 9.08 & 8.18 \\
\hline $\begin{array}{l}\text { SD D (PS particles) }\left(10^{-10} *\right. \\
\left.\mathrm{m}^{2} \mathrm{~s}^{-1}\right)\end{array}$ & 0.32 & 1.15 & 0.18 & 0.11 & 0.99 \\
\hline$n$ (test runs) $\varnothing_{\text {particle }} 4.2 \mu \mathrm{m}$ & 3 & 3 & 3 & 3 & 3 \\
\hline $\begin{array}{l}D \text { (PS particles) }\left(10^{-10} *\right. \\
\left.\mathrm{m}^{2} \mathrm{~s}^{-1}\right)\end{array}$ & 7.33 & 9.39 & 14.05 & 1.63 & No diffusion \\
\hline $\begin{array}{l}\text { SD D (PS particles) }\left(10^{-10} *\right. \\
\left.\mathrm{m}^{2} \mathrm{~s}^{-1}\right)\end{array}$ & 0.32 & 1.15 & 0.18 & 1.31 & No diffusion \\
\hline
\end{tabular}

To prevent early sedimentation and accumulation of the particles at the bottom of chamber 1 before penetration of the test discs could occur, the diffusion cell was placed with a vertical aligned fluid channel on a shaker at $100 \mathrm{rpm}$ during incubation.

According to the test runs performed on peroxidase, aliquots of each sample were taken from chamber 2 of the diffusion cell after $1,2,3,6$, and 24 hours of incubation. Particle diffusion coefficients and related concentrations were subsequently quantified by a flow cytometer (Table 6 and Figures 3(c)(c1) and 3(c)(c2)).

With reference to the quantified mean values presented in Table 6 and Figures 3(c)(c1) and 3(c)(c2) diffusion of PS beads with a diameter of $1.4 \mu \mathrm{m}$ and $4.2 \mu \mathrm{m}$ could be observed through all specimens except the inhibited penetration of test discs based on Resomer RG 504 (p) $70: 30$ composites by $4.2 \mu \mathrm{m}$ beads.

Meanwhile, diffusion of PS beads with a diameter of $20 \mu \mathrm{m}$ was completely blocked by the polymer matrix of all specimens. Conclusively a general penetration threshold of all analyzed test discs was determined between $4.2 \mu \mathrm{m}$ and $20 \mu \mathrm{m}$.

Concerning the diffusion of PS beads with a diameter of $1.4 \mu \mathrm{m}$ and $4.2 \mu \mathrm{m}$ similar results were measured for all specimens based on PLA and PLGA composites. Starting with around $10^{5}$ to $10^{8}$ diffused $1.4 \mu \mathrm{m}$ beads $/ \mathrm{mL}$ within the first hour of incubation the concentration of diffused particles remained almost unchanged during the upcoming 23 hours of incubation. An exception was marked by test discs made of Resomer L 210 (p) 70:30 composites that showed a constant increase of diffused particles during $24 \mathrm{~h}$ of incubation.

Diffusion rates of beads with a diameter of $4.2 \mu \mathrm{m}$ tend to similar results as measured for the $1.4 \mu \mathrm{m}$ beads but within a hundred times lower concentration range.

However, in both cases the highest diffusion rates were measured for PS (m) 65:35 samples that ended up with a final concentration of around $10^{8}$ beads $/ \mathrm{mL}(\varnothing 1.4 \mu \mathrm{m} / 4.2 \mu \mathrm{m})$ after $1 \mathrm{~h}$ of incubation but remained almost unchanged during the following $23 \mathrm{~h}$.
This effect was basically observed during most of the test runs and could be explained by clogging effects of the large PS beads that became entrapped within the polymer layer after its penetration. High diffusion rates as measured upon start of the incubation time end abruptly due to a sudden limitation of the particle mobility to pass through the test discs. In addition, agglomeration of diffused particles might have occurred before evaluation of the aliquots and therefore been detected as less countable objects by the laser beam of the flow cytometer.

\section{Conclusion}

In this work we introduced a new method approach for the encapsulation of small-sized electronic devices based on a sintering process of molded components. The applied technique for production of the capsules comprises just a few simple but modifiable work steps by which alternating results could be obtained. Accordingly, size, shape, volume, porosity, permeability, applied materials, and correlating properties of the prepared capsules are highly flexible and therefore adaptable to demands of multiple applications such as the protection of sensors used for cell culture surveillance in bioreactors or implantable systems within in the field of point-of-care testing.

Future efforts should be dedicated to further improvements of the general capsule functionality by features that are compatible with its concept design. Currently our focus lies on the embedment of agent carrying microparticles within the shell (Figure 4). A consecutive release of respective agents from these particles could either be useful to prevent biofouling processes on the capsule surface $[42,43]$ or to support self-maintenance of the embedded electronic device.

\section{Conflict of Interests}

The authors declare that there is no conflict of interests regarding the publication of this paper. 


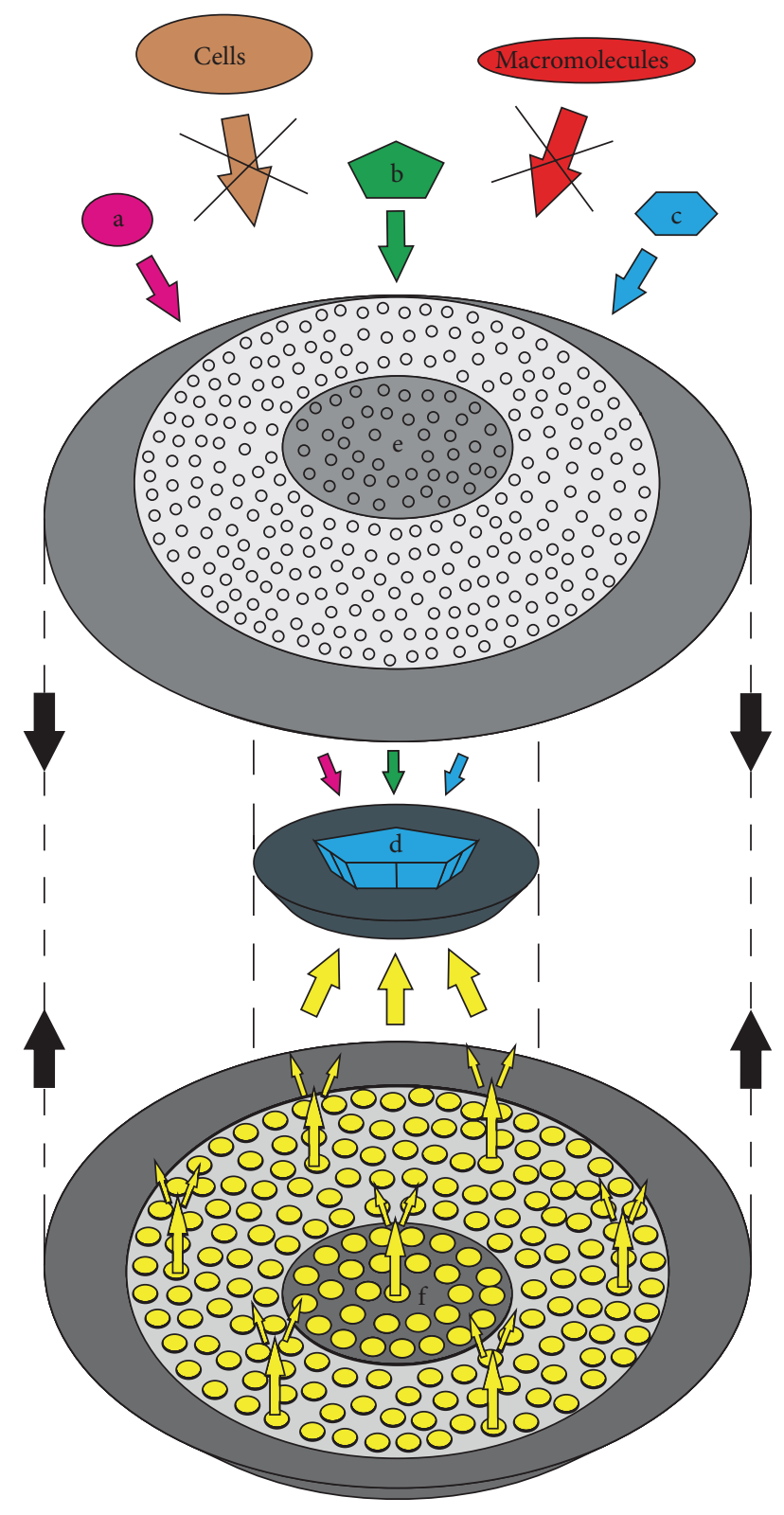

Figure 4: Capsule system with combined feature (a, b, c): analytes of interest; (d) biosensor; (e) porous upper capsule compartment; (f) entrapped micro-/nanocapsules.

\section{Acknowledgments}

The authors thank Alois Seidl and Joachim Werner from Vogt Maschinenbau $\mathrm{GmbH}$, as well as Alexander Christmann, Andre Lehmann, and Nenad Gajovic-Eichelmann from Fraunhofer Institute for Biomedical Engineering (IBMT) for technical assistance regarding the development of the capsule design and diffusion cell. This project was funded by the Ministry of Economy and Europe of the State of Brandenburg and cofunded by the European Fund for Regional Development (EFRD).

\section{References}

[1] R. D. Schmid, "Biosensoren: "Biosensoren" Von F. Scheller und F. Schubert, Birkhäuser Verlag, Basel-Boston-Berlin 1989. 352 S., Abb., Tab., geb. DM 88,-. ISBN 3-7643-2303-5," Nachrichten Aus Chemie, Technik Und Laboratorium, vol. 38, no. 6, pp. 749749, 1990.

[2] R. D. Schmid and U. Bilitewski, "Biosensoren," Chemie in Unserer Zeit, vol. 26, pp. 163-174, 1992.

[3] G. Urban, "Reinhard Renneberg and Fred Lisdat (eds.): biosensing for the 21st century," Analytical and Bioanalytical Chemistry, vol. 393, no. 3, pp. 777-778, 2009.

[4] F. F. Bier, "Biosensoren der Zukunft: in-vitro-Diagnostik im Point-of-Care-Format für die personalisierte Medizin," Deutsche Zeitschrift für Klinische Forschung, vol. 15, no. 11-12, pp. 20-25, 2011.

[5] A. Yarman, G. Gröbe, B. Neumann et al., "The aromatic peroxygenase from Marasmius rutola-a new enzyme for biosensor applications," Analytical and Bioanalytical Chemistry, vol. 402, no. 1, pp. 405-412, 2012.

[6] C. M. Thomas and J. F. Lutz, "Präzisionssynthese bioabbaubarer polymere," Angewandte Chemie, vol. 123, no. 40, pp. 9412-9414, 2011.

[7] S. V. Dorozhkin and M. Epple, "Die biologische und medizinische Bedeutung von Calciumphosphaten," Angewandte Chemie, vol. 114, no. 17, pp. 3260-3277, 2002.

[8] R. A. Jain, "The manufacturing techniques of various drug loaded biodegradable poly(lactide-co-glycolide) (PLGA) devices," Biomaterials, vol. 21, no. 23, pp. 2475-2490, 2000.

[9] W. Linhart, F. Peters, W. Lehmann et al., "Biologically and chemically optimized composites of carbonated apatite and polyglycolide as bone substitution materials," Journal of Biomedical Materials Research, vol. 54, no. 2, pp. 162-171, 2001.

[10] D. Bendix, "Chemical synthesis of polylactide and its copolymers for medical applications," Polymer Degradation and Stability, vol. 59, no. 1-3, pp. 129-135, 1998.

[11] K. Schwarz and M. Epple, "A detailed characterization of polyglycolide prepared by solid-state polycondensation reaction," Macromolecular Chemistry and Physics, vol. 200, no. 10, pp. 2221-2229, 1999.

[12] J. M. Moran, D. Pazzano, and L. J. Bonassar, "Characterization of polylactic acid-polyglycolic acid composites for cartilage tissue engineering," Tissue Engineering, vol. 9, no. 1, pp. 63-70, 2003.

[13] N. Kumar, M. N. V. Ravikumar, and A. J. Domb, "Biodegradable block copolymers," Advanced Drug Delivery Reviews, vol. 53, no. 1, pp. 23-44, 2001.

[14] M. Penco, S. Marcioni, P. Ferruti, S. D’Antone, and R. Deghenghi, "Degradation behaviour of block copolymers containing poly(lactic-glycolic acid) and poly(ethylene glycol) segments," Biomaterials, vol. 17, no. 16, pp. 1583-1590, 1996.

[15] N. Wang, X. S. Wu, C. Li, and M. F. Feng, "Synthesis, characterization, biodegradation, and drug delivery application of biodegradable lactic/glycolic acid polymers: I. Synthesis and characterization," Journal of Biomaterials Science, Polymer Edition, vol. 11, no. 3, pp. 301-318, 2000.

[16] X. S. Wu and N. Wang, "Synthesis, characterization, biodegradation, and drug delivery application of biodegradable lactic/glycolic acid polymers. Part II: biodegradation," Journal of Biomaterials Science, Polymer Edition, vol. 12, no. 1, pp. 21-34, 2001. 
[17] C. W. Hayes and W. F. Conway, "Calcium hydroxyapatite deposition disease," Radiographics, vol. 10, no. 6, pp. 1031-1048, 1990.

[18] J. Braunecker, M. Baba, G. E. Milroy, and R. E. Cameron, “The effects of molecular weight and porosity on the degradation and drug release from polyglycolide," International Journal of Pharmaceutics, vol. 282, no. 1-2, pp. 19-34, 2004.

[19] Y.-C. Wang, M.-C. Lin, D.-M. Wang, and H.-J. Hsieh, "Fabrication of a novel porous PGA-chitosan hybrid matrix for tissue engineering," Biomaterials, vol. 24, no. 6, pp. 1047-1057, 2003.

[20] R. Yang, T. Chen, H. Chen, and W. Wang, "Microfabrication of biodegradable (PLGA) honeycomb-structures and potential applications in implantable drug delivery," Sensors and Actuators $B$, vol. 106, no. 2, pp. 506-511, 2005.

[21] T. Ponnusamy, L. B. Lawson, L. C. Freytag, D. A. Blake, R. S. Ayyala, and V. T. John, "In vitro degradation and release characteristics of spin coated thin films of PLGA with a "breath figure” morphology," Biomatter, vol. 2, no. 2, pp. 77-86, 2012.

[22] I. Banerjee, D. Mishra, and T. K. Maiti, "PLGA microspheres incorporated gelatin scaffold: microspheres modulate scaffold properties," International Journal of Biomaterials, vol. 2009, Article ID 143659, 9 pages, 2009.

[23] V. K. Nandagiri, P. Gentile, V. Chiono et al., "Incorporation of PLGA nanoparticles into porous chitosan-gelatin scaffolds: influence on the physical properties and cell behavior," Journal of the Mechanical Behavior of Biomedical Materials, vol. 4, no. 7, pp. 1318-1327, 2011.

[24] H. J. Chung and T. G. Park, "Surface engineered and drug releasing pre-fabricated scaffolds for tissue engineering," Advanced Drug Delivery Reviews, vol. 59, no. 4-5, pp. 249-262, 2007.

[25] M. Epple and O. Herzberg, "Porous polyglycolide," Journal of Biomedical Materials Research, vol. 43, no. 2, pp. 83-88, 1998.

[26] M. Epple and O. Herzberg, "Polyglycolide with controlled porosity: an improved biomateria," Journal of Materials Chemistry, vol. 7, pp. 1037-1042, 1997.

[27] A. Tschakaloff, H. W. Losken, R. von Oepen et al., "Degradation kinetics of biodegradable DL-polylactic acid biodegradable implants depending on the site of implantation," International Journal of Oral and Maxillofacial Surgery, vol. 23, no. 6, part 2, pp. 443-445, 1994.

[28] A. G. Jimoh, D. L. Wise, J. D. Gresser, and D. J. Trantolo, "Pulsed FSH release from an implantable capsule system," Journal of Controlled Release, vol. 34, no. 2, pp. 87-95, 1995.

[29] H. Qiu, J. Yang, P. Kodali, J. Koh, and G. A. Ameer, "A citric acid-based hydroxyapatite composite for orthopedic implants," Biomaterials, vol. 27, no. 34, pp. 5845-5854, 2006.

[30] S. Weihe, C. Rasche, C. Schiller et al., "Individual implants of biodegradable composites for the reconstruction of skull defects," Materialwissenschaft und Werkstofftechnik, vol. 35, no. 4, pp. 224-228, 2004.

[31] C. M. Agrawal and K. A. Athanasiou, "Technique to control $\mathrm{pH}$ in vicinity of biodegrading PLA-PGA implants," Journal of Biomedical Materials Research, vol. 38, no. 2, pp. 105-114, 1997.

[32] J. Raba and H. A. Mottola, "Glucose oxidase as an analytical reagent," Critical Reviews in Analytical Chemistry, vol. 25, no. 1, pp. 1-42, 1995.

[33] J. Wang, "Glucose biosensors: 40 years of advances and challenges," Electroanalysis, vol. 13, no. 12, pp. 983-988, 2001.

[34] J. Tanne, D. Schäfer, W. Khalid, W. J. Parak, and F. Lisdat, "Lightcontrolled bioelectrochemical sensor based on CdSe/ZnS quantum dots," Analytical Chemistry, vol. 83, no. 20, pp. 7778-7785, 2011.
[35] A. K. J. Goka and M. J. G. Farthing, "The use of 3,3',5,5' tetramethylbenzidine as a peroxidase substrate in microplate enzyme-linked immunosorbent assay," Journal of Immunoassay, vol. 8, no. 1, pp. 29-41, 1987.

[36] R. W. Bally and T. C. Gribnau, "Some aspects of the chromogen $3,3^{\prime}, 5,5^{\prime}$-tetramethylbenzidine as hydrogen donor in a horseradish peroxidase assay," Journal of Clinical Chemistry \& Clinical Biochemistry, vol. 27, no. 10, pp. 791-796, 1989.

[37] S. A. M. Van Stroe-Biezen, F. M. Everaerts, L. J. J. Janssen, and R. A. Tacken, "Diffusion coefficients of oxygen, hydrogen peroxide and glucose in a hydrogel," Analytica Chimica Acta, vol. 273, no. 1-2, pp. 553-560, 1993.

[38] A. N. Bashkatov, E. A. Genina, Y. P. Sinichkin, V. I. Kochubey, N. A. Lakodina, and V. V. Tuchin, "Glucose and mannitol diffusion in human dura mater," Biophysical Journal, vol. 85, no. 5, pp. 3310-3318, 2003.

[39] A. Converti, M. Casagrande, M. De Giovanni, M. Rovatti, and M. Del Borghi, "Evaluation of glucose diffusion coefficient through cell layers for the kinetic study of an immobilized cell bioreactor," Chemical Engineering Science, vol. 51, no. 7, pp. 1023-1026, 1996.

[40] K. Groebe, S. Erz, and W. Mueller-Klieser, "Glucose diffusion coefficients determined from concentration profiles in EMT6 tumor spheroids incubated in radioactively labeled L-glucose," Advances in Experimental Medicine and Biology, vol. 361, pp. 619-625, 1994.

[41] A. Fatima and Q. Husain, "Purification and characterization of a novel peroxidase from bitter gourd (Momordica charantia)," Protein and Peptide Letters, vol. 15, no. 4, pp. 377-384, 2008.

[42] A. Iannitelli, R. Grande, A. Di Stefano et al., "Potential antibacterial activity of carvacrol-loaded poly(DL-lactide-coglycolide) (PLGA) nanoparticles against microbial biofilm," International Journal of Molecular Sciences, vol. 12, no. 8, pp. 5039-5051, 2011.

[43] S.-M. Niemelä, I. Ikäheimo, M. Koskela et al., "Ciprofloxacinreleasing bioabsorbable polymer is superior to titanium in preventing Staphylococcus epidermidis attachment and biofilm formation in vitro," Journal of Biomedical Materials Research B, vol. 76, no. 1, pp. 8-14, 2006. 

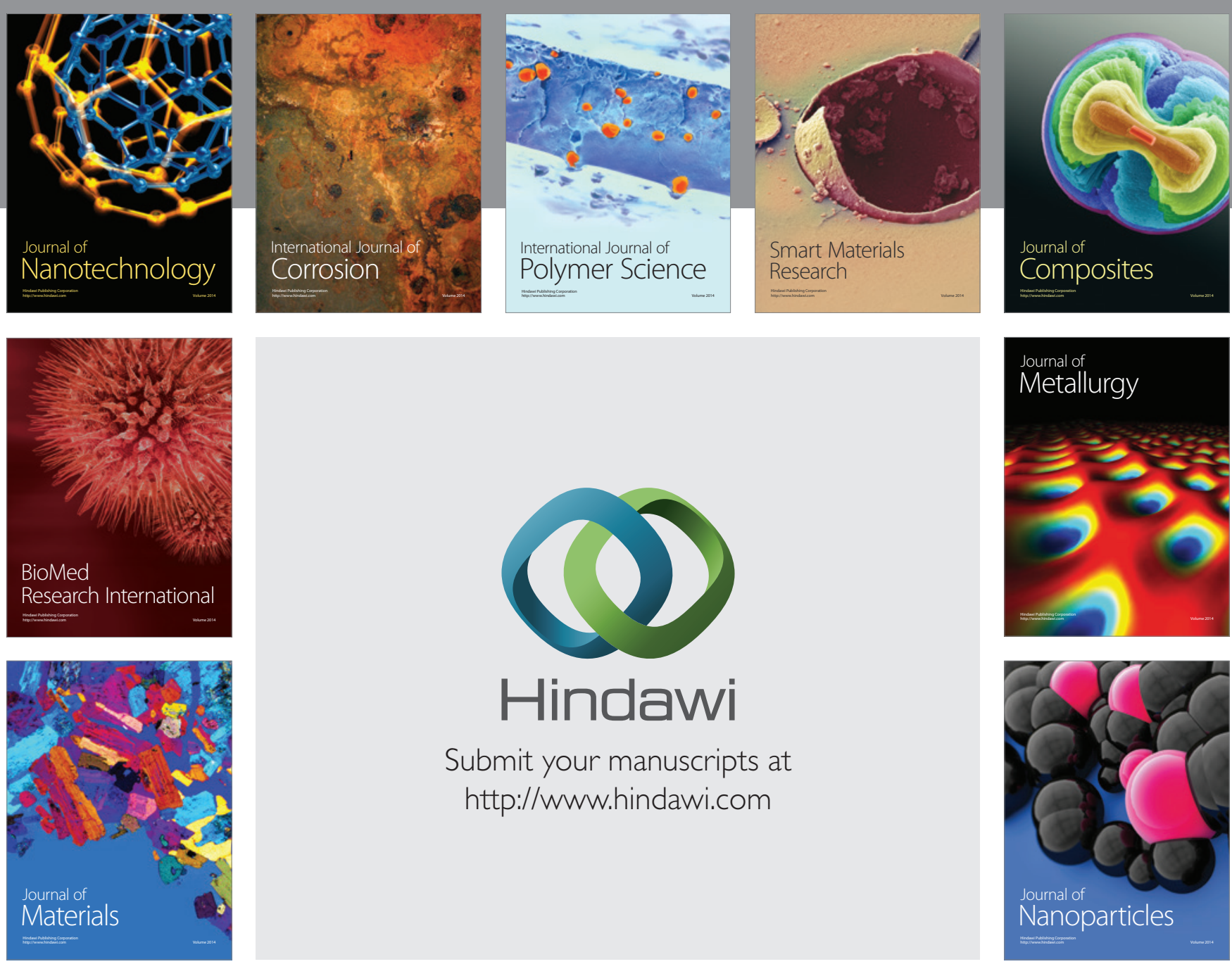

Submit your manuscripts at http://www.hindawi.com
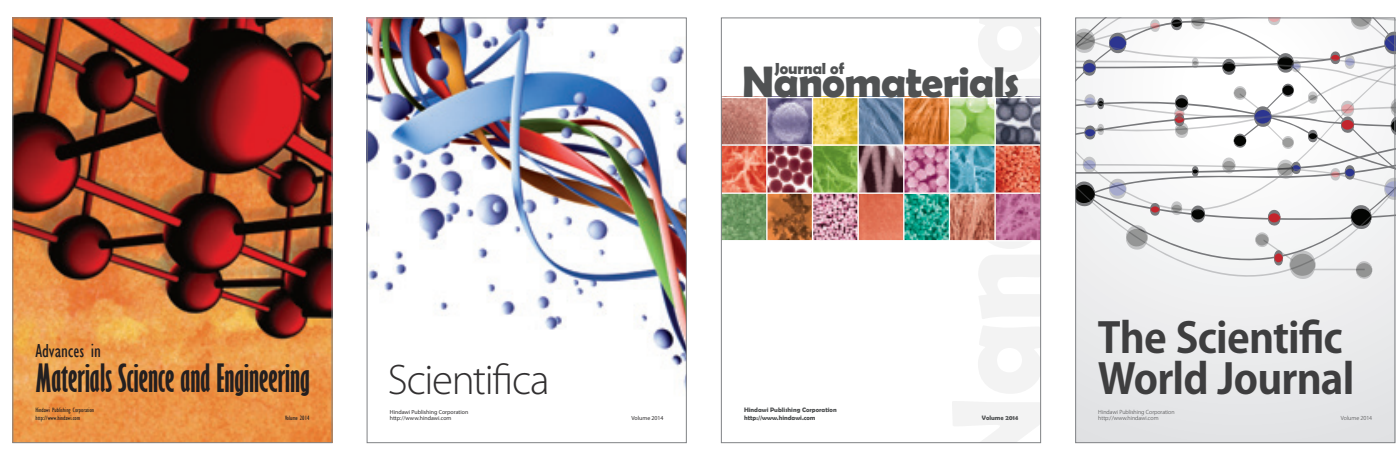

\section{The Scientific World Journal}
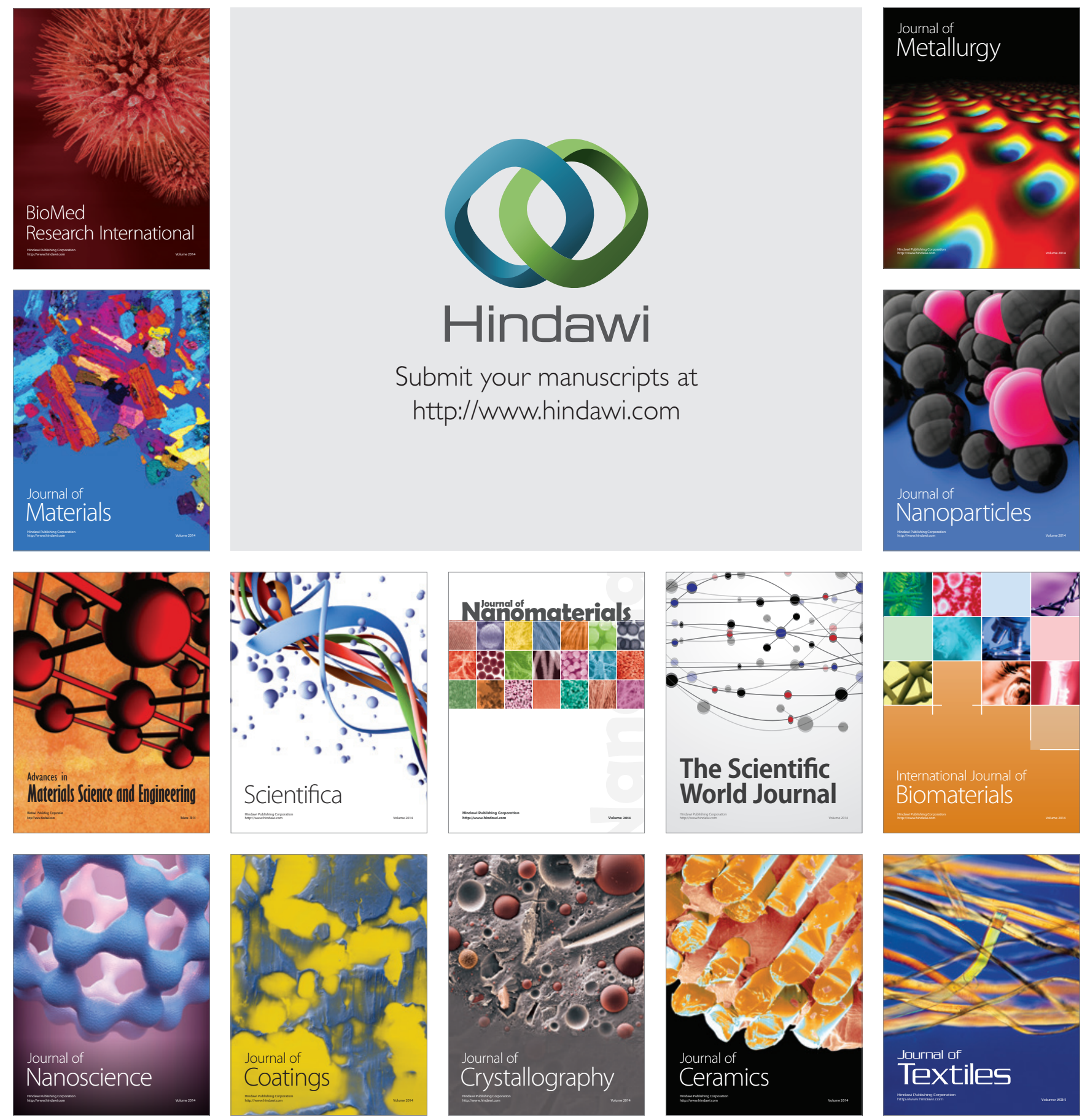